\title{
Exploring the Potential of Home Energy Monitors for Transactive Energy Supply Arrangements
}

\author{
Andrea Taylor ${ }^{1}$, Bruce Stephen ${ }^{2}$, Craig Whittet $^{1}$, Stuart Galloway ${ }^{2}$ \\ ${ }^{1}$ The Glasgow School of Art, Glasgow, UK \\ \{A.Taylor, C.Whittet\}@gsa.ac.uk \\ ${ }^{2}$ University of Strathclyde, Glasgow, UK \\ \{Bruce.Stephen, Stuart.Galloway\}@strath.ac.uk
}

\begin{abstract}
There has been considerable investment in micro energy generation from both domestic consumers and small-scale providers. However, current metering arrangements and home energy monitoring products are too basic to enable real-time billing and remuneration, limiting the effectiveness of this investment. This paper describes the exploration of home energy monitors as a technical enabler to unlock the local trading potential of the investment in micro energy generation, and the human factors involved in interacting with these products that might pose obstacles to successful uptake. First, a human factors analysis of eight home energy monitors was conducted, which identified a number of usability issues. Next, a range of design concepts were developed to address the key usability problems identified, incorporate the forward-looking facility for alternative energy supply models, and stimulate further investment in energy prosumption. This study contributes an understanding of the potential of home energy monitors for transactive energy supply arrangements.
\end{abstract}

Keywords: Human Factors · Energy Transactions · Interface Design · Product Design Engineering

\section{Introduction}

The UK Government has legislated ambitious policies to reduce greenhouse gases, with the Climate Change Act (2008) mandating emissions reductions from 1990 levels of $34 \%$ by 2020 and $80 \%$ by 2050 [1]. The resulting penetrations of small scale low carbon technologies including renewable energy sources and distributed storage have led to resilience driven aspirations of decentralized power system control and operation at local and neighbourhood level. Although not currently realized, coordination of local distributed generation sources and a greater degree of demand flexibility offers the potential to lower the cost of energy at source and to enable remuneration for consumer participation, addressing rising costs of energy supply which impacts strongly on all consumers, in particular the fuel poor.

Realizing consumer participation in the delivery of energy services in the UK currently has a number of barriers in the form of limited metering resolution at settlement points, regulation governing retail and demand response services being limited to only the largest energy users (e.g. industrial customers). Power demand and supply from 
residential buildings is a domain of growing complexity as on-site renewables, heat and electricity storage and electric vehicles begin to gain popularity at distribution network level. Understanding how highly variable household power demand and supply, driven by stochastic occupant behaviours and influenced by new technologies, can be integrated with energy trading technology is a key challenge. By far the greatest barrier though to end user participation in power system operation is the overhead associated with dealing with large numbers of small players: aggregate contributions would provide a valuable operational response but the size of cohort required to provide it would generate transaction cost overheads far greater than the value. Automation provides a solution to this, but for the householder, how this can interface in a transparent and intuitive manner is an additional obstacle to implementation [2].

Technological enablers are required though that will address the technical and social issues surrounding the use of automated technology for energy supply and services. Existing models use a very conservative point-measurement/central-billing method that is supported by usage estimates to determine customer bills. This often leads to a breakdown of trust in the sector. Furthermore, the quarterly or monthly resolution at which bills are produced has compounded this trust through lack of transparency. Moving to a digitized based settlement process combined with automation ${ }^{1}$ makes multiple small transactions possible, supported by higher resolution metering. Suppliers and consumers authenticating such systems instill trust in the business arrangement. Finally, secure digitized solutions can support much more representative billing algorithms, allowing for dynamic pricing throughout the day and thus short term economic support for demand side response (the use of demand flexibility to address shortfalls or surpluses of generation as might be expected from intermittent renewable sources) [3].

\subsection{The Study}

The EPSRC (Engineering and Physical Sciences Research Council) project TESA (Transactive Energy Supply Arrangements) aimed to landscape the social, technical, regulatory, and design pathways to enable the future supply of energy to customers that will further stimulate investment in electricity generation both from small-scale providers and customers themselves, reducing the demand for large-scale infrastructure investments [4]. A key objective of the TESA project was to inform on the enablers and obstacles for future energy supply arrangements at the neighbourhood level as a means of supporting the 'people' side of digital transactive models. This study explored the potential of home energy monitors, formally known as In Home Displays (IHDs), as a technical enabler to unlock the local trading potential of the investment in micro energy generation (small-scale power generation) from both domestic consumers and small-scale providers, and the human factors currently involved in interacting with these products that might pose obstacles to successful uptake. The infor-

\footnotetext{
${ }^{1}$ According to a study reported in IEEE Spectrum (Oct 2017), many major companies are working on integrating Blockchain Technology into their products. This is seen as a disruptive development as we move towards a more 'digital future' and at the macro level it is seen as a better way, a more cost effective way, of managing data and trust interfaces.
} 
mation that will enable engagement in future energy supply arrangements is multifaceted and has to be presented carefully, and with consideration to the householder. The aim is to avoid placing an excessive burden on householders through their interaction with energy products. The study builds on and extends our previous work, which involved a practical review of energy saving technology for ageing populations [5].

Home energy monitors are designed to increase householders' awareness and understanding of energy usage, connecting routine behaviour to consumption in order to motivate conservation behaviour and reduce energy bills. Home energy monitors are commercially available or provided by energy suppliers when installing a smart meter. Commercially available energy monitors are typically made up of three parts: an in home display, a sensor, and a transmitter. The householder is required to clamp the sensor on to a power cable connected to the electricity meter, which measures the current passing through it. The transmitter sends the data wirelessly to the display unit. Energy monitors provided by energy suppliers also incorporate wireless transmission to connect to an in-home display [6], however householders are not required to install the technology. Typically, electricity usage is displayed in units of energy used $(\mathrm{kWh})$, cost $(£)$ or carbon emissions $(\mathrm{CO} 2)$. In the UK, in home displays are required by standard to provide tariff information, consumption, time of day and in some cases information pertaining to remaining credit. Some displays offer additional features such as alerts when a set amount of electricity has been used.

\section{$2 \quad$ Method}

The research was conducted by 20 Product Design Engineering students from The Glasgow School of Art and University of Glasgow in the UK, in 2017, supported by academic staff working on the TESA project. Each student selected a user group to focus their research on, primarily based on who they deemed likely to practice and benefit from 'energy prosumption' (production and consumption of energy) in the future. The students then identified and recruited a small group of householders to take part in the study, mostly through their social networks, who matched the profile of their chosen user group. The user groups included: students/young people living in shared accommodation who value the environment and live on a budget; family home owners (all ages: young to elderly people) who produce or plan to produce renewable energy; and young professionals who value the environment and have a disposable income to invest in renewable energy devices and technologies in their home. Approximately 110 householders living in residential areas of South West Scotland participated in the study. Actively engaging with householders at all stages of the study helped to ensure the likelihood that the resulting design concepts and future scenarios are both fit for purpose and desirable for the people who will use them.

\subsection{Human Factors Analysis}

Working individually or in small teams, the students conducted a human factors analysis of eight home energy monitors: Amphiro B1 Connect by Amphiro [7], Elite Classic by Efergy [8], EM02 Power Meter by TACKLife [9], In Home Display by Scottish Power [10], Minim+ by geo [11], OWL +USB by OWL [12], OWL Micro+ by OWL 
[13], and Smart Energy Tracker by Scottish and Southern Energy (SSE) [14]. The Amphiro B1 Connect is somewhat different to the other products reviewed in that it monitors energy consumption from a particular device: a shower. The product fits directly to the shower and displays the current water consumption and temperature. The other products reviewed monitor electricity consumption in the home. Additionally, the In Home Display by Scottish Power and the Smart Energy Tracker by SSE monitor gas consumption. None of the existing product base currently utilizes blockchain technology, and none of the products reviewed monitor energy generated by renewable sources such as solar panels. The monitors were chosen to provide an overview of the market sector: none were supplied by manufacturers or sales agents.
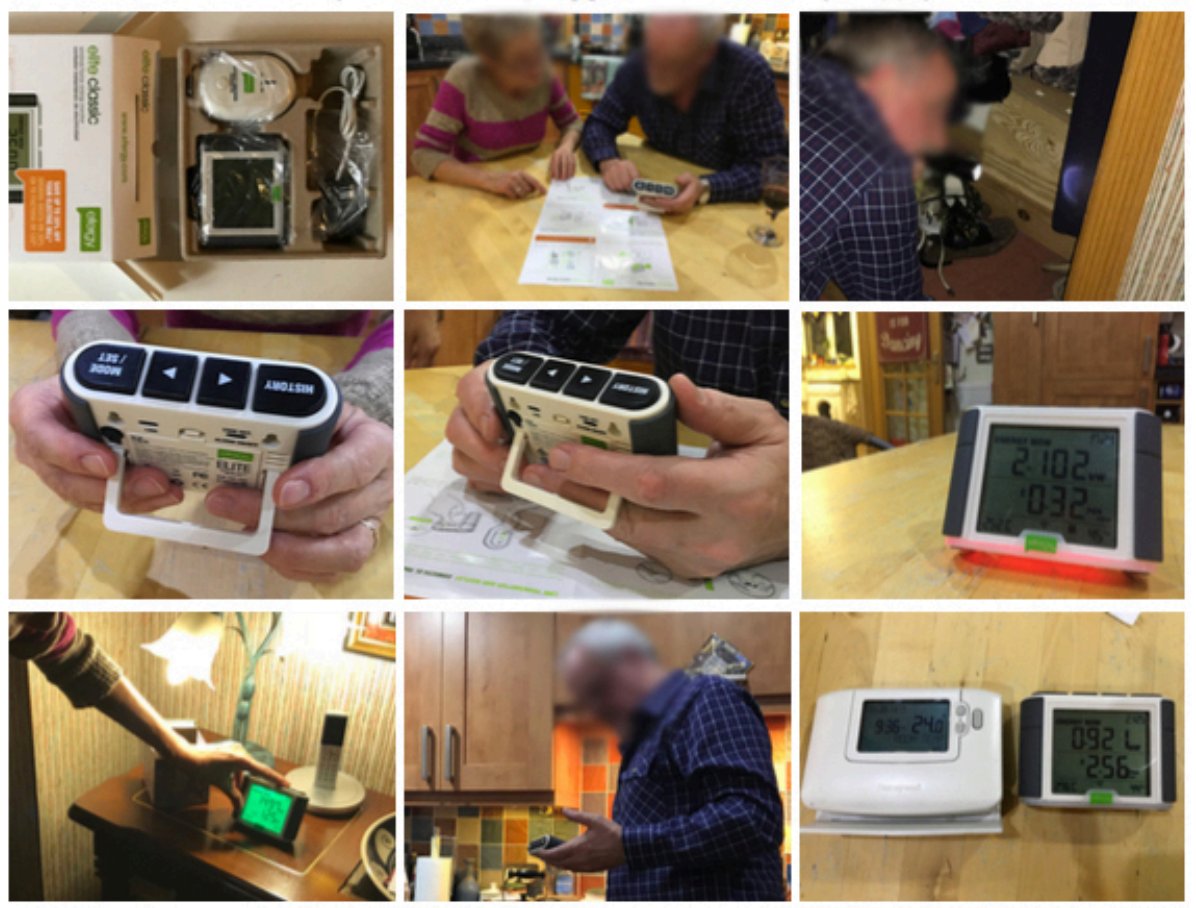

Fig. 1. Observations of an elderly couple setting up a home energy monitor.

The analysis itself was exploratory. First, a high-level task analysis was conducted based on the 'out of the box' product experience. This included everything from the process of unpacking and revealing the product for the first time to installing (if required), configuring and operating it (Fig 1). Procedures and processes were documented, and a high-level sequential task description was produced. Next, the highlevel task analyses were used to define representative scenarios that covered all aspects of energy monitoring. The students then took each product/scenario, and working with participants, performed a verbalized/observed product walkthrough using the procedure laid down in [15]. The full spectrum of scenarios, from unpacking to operating the product were covered, and the scenarios were frozen at key points to allow for in-depth questioning. Key insights were documented, recorded and/or photo- 
graphed as appropriate. Finally, procedures and processes identified during the product walkthrough as being particularly problematic were subject to further research. The students selected from a range of 12 established usability methods (Table 1) to develop a more tailored analysis, primarily based on the issues discovered and the insights that each method is designed to provide.

At the conclusion of the data collection phase, the students and principle investigators convened and undertook a presentation workshop in order to synthesise, cross check and group the findings.

Table 1. The analysis of the energy monitors involved selecting from 12 methods.

\begin{tabular}{|c|c|}
\hline Method & Insights Provided \\
\hline Heuristics (e.g. [16]) & $\begin{array}{l}\text { A flexible subjective approach in which observations during product } \\
\text { usage are recorded. }\end{array}$ \\
\hline $\begin{array}{l}\text { Immersion Analysis } \\
\text { (e.g. [17]) }\end{array}$ & $\begin{array}{l}\text { Immersion in the research process from the point of view of the user } \\
\text { for design empathy and insight e.g. simulation of physical disabili- } \\
\text { ties. }\end{array}$ \\
\hline Focus Groups (e.g. [18]) & $\begin{array}{l}\text { Group interviews where participants are selected on the basis they } \\
\text { would have something to say on the topic and would be comfortable } \\
\text { talking to the interviewer and to each other. }\end{array}$ \\
\hline $\begin{array}{l}\text { Semi-Structured Inter- } \\
\text { views (e.g. [15]) }\end{array}$ & $\begin{array}{l}\text { Pre-ordered questions and themes presented to participants by the } \\
\text { interviewer, but with scope to branch off into other relevant areas as } \\
\text { required. }\end{array}$ \\
\hline $\begin{array}{l}\text { Function Flow Diagrams } \\
\text { (e.g. [19]) }\end{array}$ & $\begin{array}{l}\text { Graphical representation of device function and events that occur } \\
\text { during the performance of a task. }\end{array}$ \\
\hline $\begin{array}{l}\text { Abstract Hierarchy (e.g. } \\
[20])\end{array}$ & $\begin{array}{l}\text { A model of the system in terms of a hierarchy of functions, from the } \\
\text { most abstract of functions to the most local of processes, and their } \\
\text { relationships to one another. }\end{array}$ \\
\hline $\begin{array}{l}\text { Microsoft Product Reac- } \\
\text { tion Cards (e.g. [21]) }\end{array}$ & $\begin{array}{l}\text { A set of cards with a word (adjective) written on each card that } \\
\text { participants are asked to select from to describe their response to a } \\
\text { product. }\end{array}$ \\
\hline Personas (e.g. [17]) & $\begin{array}{l}\text { A synthesis of the full participant pool into a subset of fictional } \\
\text { characters that embody the dominant traits in the sample. }\end{array}$ \\
\hline $\begin{array}{l}\text { Cambridge Impairment } \\
\text { Simulator (e.g. [22]) }\end{array}$ & $\begin{array}{l}\text { Filters are applied to image and sound files to simulate some of the } \\
\text { main effects of common visual and hearing impairments. }\end{array}$ \\
\hline $\begin{array}{l}\text { Co-Creation/Video } \\
\text { Prototypes (e.g. [17]) }\end{array}$ & $\begin{array}{l}\text { Visual prototypes that are taken to participants in order to gather } \\
\text { initial design feedback. }\end{array}$ \\
\hline Photo Diary (e.g. [17]) & $\begin{array}{l}\text { A technique whereby participants themselves can take photos of } \\
\text { device issues as they are encountered over a longer time period and } \\
\text { without an analyst being present. }\end{array}$ \\
\hline $\begin{array}{l}\text { Design with Intent } \\
\text { Toolkit (e.g. [23]) }\end{array}$ & $\begin{array}{l}\text { Cards and worksheets that act as different 'lenses' through which } \\
\text { common problems can be viewed and new perspectives gained. }\end{array}$ \\
\hline
\end{tabular}

\subsection{Design Concepts and Future Scenarios}

Based on the results of the human factors analysis, the students explored and developed a set of design concepts and future scenarios to: address the key usability problems identified during the human factors analysis, incorporate the forward-looking facility for true transactive energy supply arrangements, and stimulate further invest- 
ment in energy prosumption (production and consumption of energy). An iterative design methodology was adopted, involving the continual improvement of the design concepts. First, each student brainstormed ideas. They then selected a design concept for further development and generated low-fidelity prototypes e.g. sketches and foam models. Next, the concept was presented to several participants as test users, any problems and opportunities were noted, and the concept was evaluated and refined accordingly. As required (time permitting), the students repeated the preceding step until the design concept was resolved to a level required for final presentation.

\section{Results}

\subsection{Human Factors Analysis: Key Problems Identified}

The human factors analysis identified a number of usability problems with the home energy monitors reviewed, some of which were discovered in our earlier practical review of energy saving technology for ageing populations [5]. This is perhaps not too surprising as three of the products reviewed were the same in both studies: Elite Classic, OWL Micro+ and OWL +USB. However, our earlier review was conducted in 2012, five years prior to the current study, and it is disappointing to discover that little progress has been made on these issues. The key problems identified were:

- Accessing the electricity meter if it is located in a hard-to-reach/dark location

- Identifying the main power cable from the other electrical cables

- Attaching the sensor to the power cable e.g. due to the stiffness of the clip

- Following the set-up instructions e.g. due to a large volume of text

- Finding/understanding tariff information (needed for an accurate display of cost)

- Pairing the transmitter and the display

- Operating awkward to reach controls e.g. buttons located at the rear of the display

- $\quad$ Reading fixed LCD screens with narrow viewing angles and no backlighting

- Understanding electricity usage when expressed as $\mathrm{kWh}$ or $\mathrm{CO} 2$

- Understanding visually busy information displays

- Understanding energy consumption as normal/high/low (compared to others)

- Knowing how to save energy based on the information provided

- Losing interest with the monitor e.g. due to lack of noticeable feedback

- Finding the monitor aesthetically unattractive

- Setting up profiles (accounts) for individual members of a household.

A range of design concepts were developed to address the key problems identified with the energy monitors reviewed. For example, one concept proposed a 'tips' information screen that provides personalized suggestions on how to save energy based on appliance usage (Fig. 2 left); and a second concept proposed a display with illuminated edges that change colour along a spectrum of blue to red, to provide noticeable information 'at a glance' on current energy usage e.g. a change to red provides a visual cue that usage levels are high (Fig. 2 right). 

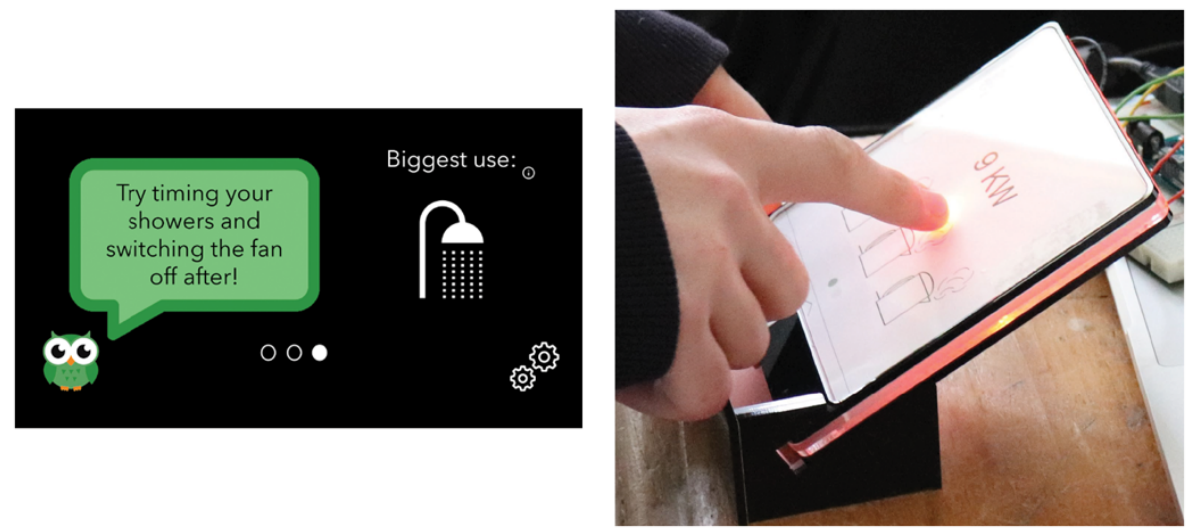

Fig. 2. Design concepts were developed to address the key usability problem.

\subsection{Design Concepts and Future Scenarios}

A wide range of design concepts were explored and developed. In particular, concepts focused on provision for neighbours to trade energy directly, more efficiently, with each other; new interfaces for energy forecasting (demand and pricing) to incentivize householders to use energy during periods of high production and low demand; and new interfaces to incentivize householders to generate renewable energy, fitting in with the alternative transactive models of TESA. Generally, the scenarios assume that energy suppliers will have installed smart meters in all households, and tariffs will be based on the time of day where energy suppliers charge more at times of low energy production and high energy demand, and vice versa, in order to help reduce strain on the national power grid. Time of use tariffs are already available in some countries (most notably France) and will become more flexible as technology permits, although there is a risk of 'information overload' for the householder [24].

Provision for Neighbours to Trade Energy Directly. Several of the design concepts explored local market trading between domestic prosumers (households who produce and consume energy) at the neighbourhood level. For example, the OWL solar+ concept is designed for a potential future where Government has, through subsidies, funded installation of solar panels on the rooftops of blocks of flats [25]. In this scenario, energy generated by the solar panels is split equally between the flats as a network. The $O W L$ solar+ encourages householders to share (and request) surplus energy with neighbours, in the spirit of community, as any unused energy is fed into the conventional power grid. The $H u b$ concept similarly enables neighbours to trade energy (Fig. 3). The interface includes options for householders to select how much electricity or water they want to trade and to negotiate a price with a neighbour. The interface also includes a weather forecast (e.g. amount of rain expected to fall in the next few days) to aid decision-making. 

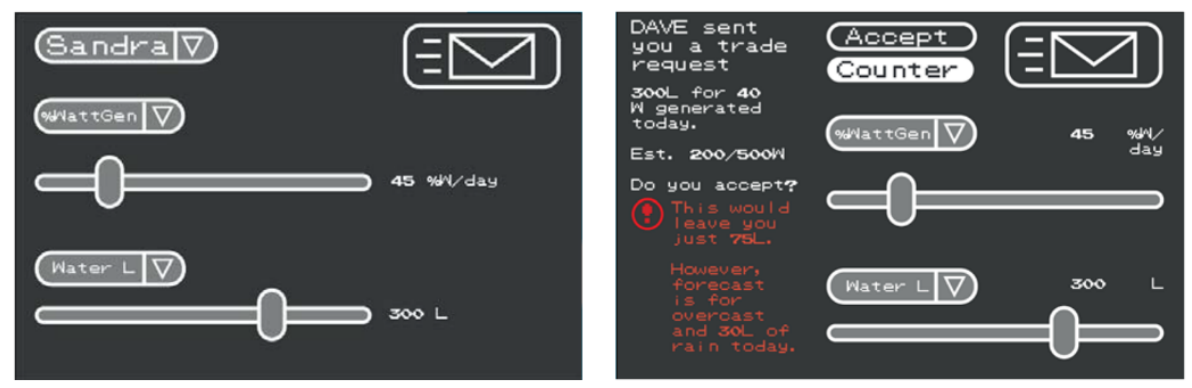

Fig. 3. The $H u b$ concept allows neighbours to trade electricity or water.
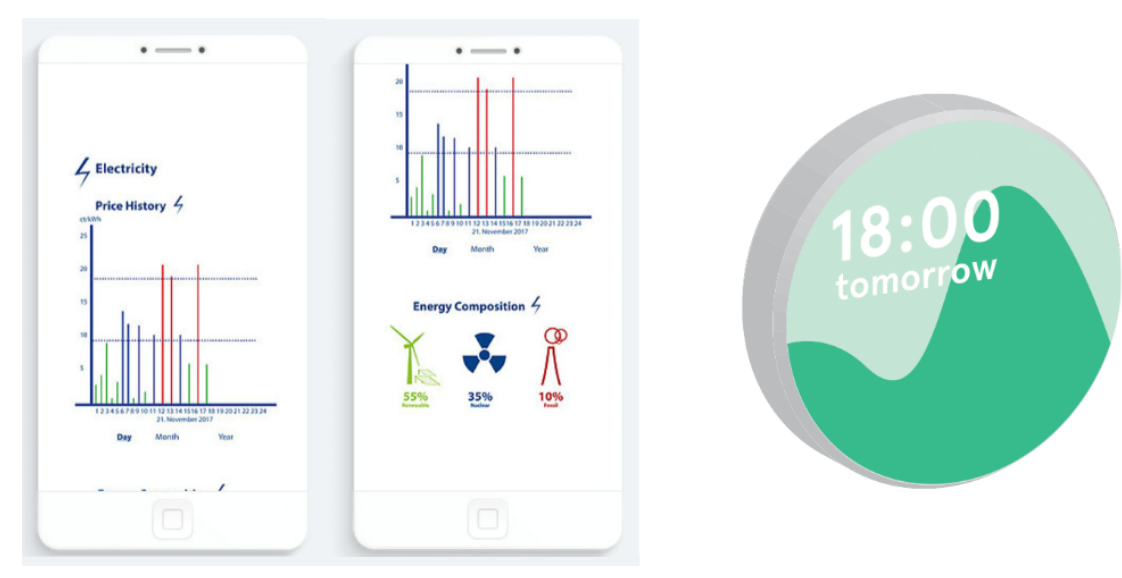

Fig. 4. The EnergyApp concept (left) displays energy forecast and energy composition diagrams. The $C L U$ concept (right) displays predicted production peaks in renewable energy.

New Interfaces for Energy Forecasting. Residential energy use is very diverse and follows the routines of dwelling occupants rather than localized trends making it difficult to predict and accommodate [26]. To persuade householders to follow neighbourhood group patterns, a common directive could be imparted through an in home display. Consequently, other design concepts explored new interfaces for energy forecasting to incentivize householders to use energy during periods of high production and low demand, and to highlight the opportunity to use affordable and clean energy. For example, the EnergyApp concept displays the current price of energy, colourcoded to communicate 'at a glance' when prices are high or low, and the predicted price of energy over the upcoming period (Fig. 4). In addition, the EnergyApp displays a percentage breakdown of how energy is currently being generated (\% renewable energy, fossil fuels, nuclear) to encourage householders to consume energy, e.g. charge their electric car, when levels of renewable energy are high. The CLU concept is designed for a potential future where there is an increase in communal living (coliving) as a solution to the problem of population growth, and in particular, the large percentage of the population living in cities. The monitor, which is designed for 
communal use, displays predicted peaks in energy generated by renewable sources, giving householders the opportunity to choose clean energy.

New Interfaces to Incentivize Householders to Produce Renewable Energy. Several of the design concepts explored how householders might be incentivized to generate renewable energy. For example, the Future of Energy Monitoring and Exchange concept is designed for a potential future where householders require to be convinced of the cost-benefit of producing energy. In this scenario, Government will fund solar panels to be installed on local government buildings (e.g. community centre, library), and households in the vicinity will be given an energy monitor to buy (and trade) energy with these buildings, thereby supporting local services, or from (and with) neighbours who produce energy. A motivational feature of the interface is notification of how much energy could be produced if the householder installed solar panels. The Social Energy Network concept is designed for a potential future where communities use energy generated by the community rather than a conventional energy provider (Fig. 5). The interface incentivizes householders to produce renewable energy by making it easy to trade with neighbours and by giving more control. A key layout provides a graphical overview of those neighbours who are on the network and how much energy they wish to trade; selecting a neighbour opens a dialog box with more details on, and options to, conduct the transaction.

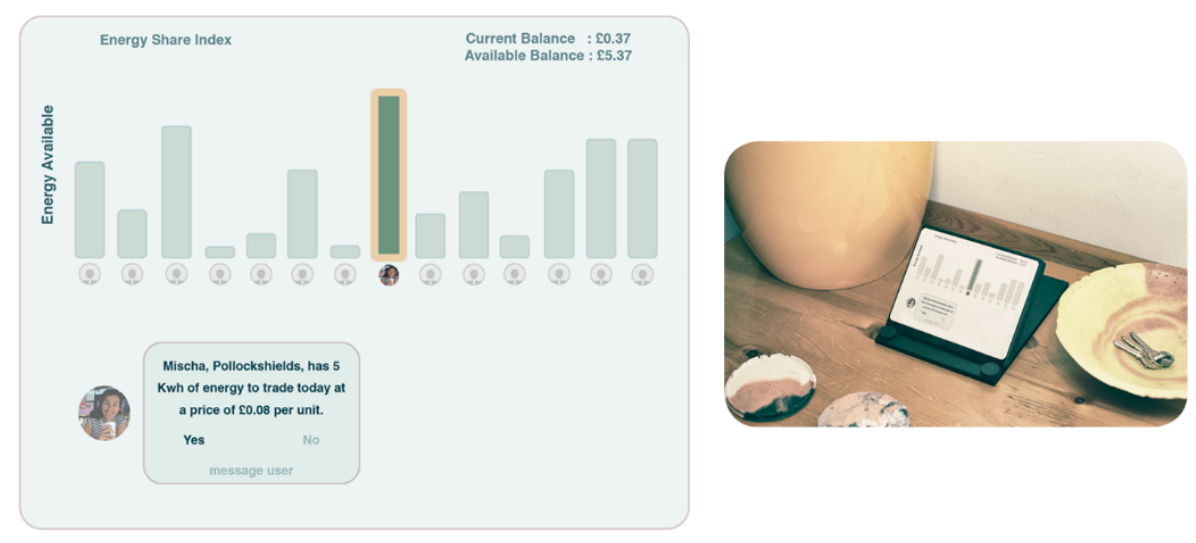

Fig. 5. The Social Energy Network is designed for a community of domestic prosumers.

\section{Conclusion}

Transacting directly with consumers and small-scale providers deep into utility networks in an economically viable manner is currently a significant business and technological challenge with not all barriers well understood, particularly those from the perspective of human factors. This study contributes an understanding of the potential enhancement of home energy monitors to support transactive energy supply arrangements and the obstacles posed by the failure to apply human factors principles to cur- 
rent products. Low carbon generation technologies are inevitable in future energy systems meaning that intermittency must be accommodated through associated supply arrangements; in the domestic context, the householder can have the opportunity to provide this but this can only happen reliably if the interface to these arrangements is designed to make participation effortless. With the continued developments in the Internet of Things, engineering systems design and the growing sector of artificial intelligence and smart devices technologies, there is a very strong possibility that consumer choice will be further restricted by the pace of change due to the scale of the large utility providers. Through understanding consumer behavior, applying sound human factors methods, working with energy providers (all scales), and developing responsible, practical, reliable and intuitive physical and digital products, the current and future consumers of energy will have access to products that are able to meet the growing demands of the energy sector.

Acknowledgements. The study is funded by EPSRC (EP/R002312/1). We thank all those who were involved for their time and support.

\section{References}

1. UK Houses of Parliament, Climate Change Act 2008 (Chapter 27).

2. Stephen, B., Galloway, S., Burt, G.: Self-Learning Load Characteristic Models for Smart Appliances. IEEE Transactions on Smart Grid. 5, 5, 2432--2439 (2014)

3. Allison, J., Cowie, A., Galloway, S., Hand, J., Kelly, N., Stephen, B.: Simulation, Implementation and Monitoring of Heat Pump Load Shifting using a Predictive Controller. Energy Conversion and Management. 150, 890--903 (2017)

4. EPSRC, http://gow .epsrc.ac.uk/NGBOViewGrant.aspx?GrantRef=EP/R002312/1

5. Walker, G., Taylor, A., Whittet, C., Lynn, C., Docherty, C., Stephen, B., Owens, E., Galloway, S.: A Practical Review of Energy Saving Technology for Ageing Populations. Appl Ergon. 62, 247--258 (2017)

6. GOV.UK, https://www.gov.uk/government/consultations/smart-metering-equipmenttechnical-specifications-second-version

7. Amphiro, https://www .amphiro.com/en/produkt/amphiro-b1-connect/

8. Efergy, http://efergy.com/uk/elite-classic

9. TACKLife, https://www.tacklifetools.com/product/product/index/id/84

10. Scottish Power, https://www.scottishpower.co.uk/energy-efficiency/smart-meters/

11. Geo, https://www.geotogether.com/consumer/product/minim-electricity-monitor-ledsensor/

12. OWL, http://www theowl.com/index.php/energy-monitors/standalone-monitors/owlusb/

13. OWL, http://www.theowl.com/index.php?cID=185

14. SSE https://www.sse.co.uk/DXP/assets/files/SSE\%20IHD\%20Full\%20Guide\%20AUG16 $\% 20 \mathrm{cropped} . p d f$

15. Stanton, N.A., Salmon, P.M., Rafferty, L., Walker, G.H., Baber, C., Jenkins, D.P.: Human Factors Methods: A Practical Guide for Engineering and Design, Ashgate, Farnham (2013)

16. Stanton, N.A., Young, M.S.: What Price Ergonomics? Nature. 399, 197--198 (1999) 
17. Hanington, B., Martin, B.: Universal Methods of Design: 100 Ways to Research Complex Problems, Develop Innovative Ideas, and Design Effective Solutions. Rockport Publishers, Massachusetts (2012)

18. Langford, J., McDonagh, D.: What Can Focus Groups Offer Us? In: McCabe, P.T., Hanson, M.A., Robertson, S. A. (eds) Contemporary Ergonomics 2002. pp. 502--506. CRC Press (2002)

19. Kirwan, B., Ainsworth, L.K.: A Guide to Task Analysis: The Task Analysis Working Group. CRC Press (1992)

20. Naikar, N.: Work Domain Analysis: Concepts, Guidelines, and Cases. CRC Press (2013)

21. Benedek, J., Miner, T.: Measuring Desirability: New Methods for Evaluating Desirability in a Usability Lab Setting. In: Proc. Usability Professionals Association Conference, pp. 8--12. (2002)

22. Cambridge Engineering Design Centre, https://www-edc.eng.cam.ac.uk/

23. Lockton, D., Harrison, D., Stanton, N.A.: The Design with Intent Method: A Design Tool for Influencing User Behaviour. Appl. Ergon. 41, 382--392 (2010)

24. Fischer, D., Stephen, B., Flunk, A., Kreifels, N., Byskov Lindberg, K., WilleHaussmann, B., Owens, E.H: Modelling the Effects of Variable Tariffs on Domestic Electric Load Profiles by Use of Occupant Behavior Submodels. IEEE Transactions on Smart Grid. 8, 6, 1949--3053 (2017)

25. Ofgem Feed-in Tariffs, https://www.ofgem.gov.uk/environmental-programmes/fit

26. Stephen, B., Tang, X., Harvey, P.R., Galloway, S., Jennett, K.I.: Incorporating Practice Theory in Sub-Profile Models for Short Term Aggregated Residential Load Forecasting. IEEE Transactions on Smart Grid. 8, 4, 1591--1598 (2015) 